dorsum of hand and it is preserved during the harvest. Accidental injury to the nerve leads to morbidity with loss of sensation and a painful neuroma occasionally.

The SRN lies radial to the brachioradialis (BR) tendon [Figure 1] and even considered an anatomical landmark during flap harvest. But in this case, we found the nerve superficial and ulnar to the Brachioradialis (BR) tendon [Figure 2]. The septocutaneous perforators to the Radial forearm flap lies between the tendons of BR and Flexor carpi radialis (FCR). The perforators passing over the nerve were clipped [Figure 3]. Hence the nerve was dissected carefully and separated without injuring the other perforators [Figure 4].

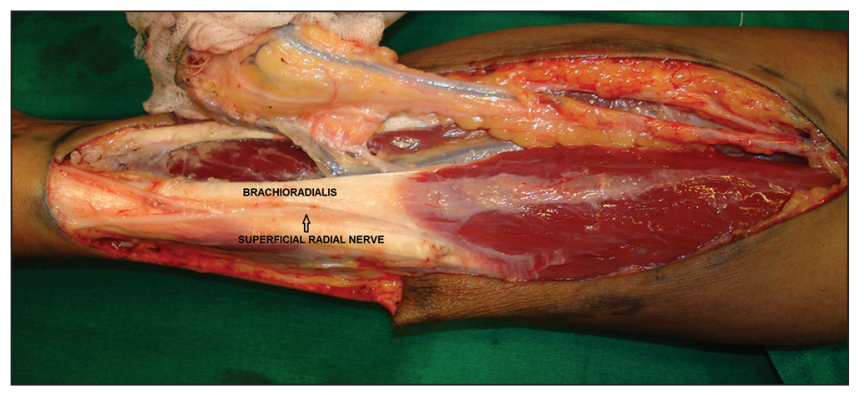

Figure 1: SRN- superficial radial nerve. Normal course of SRN is radial to Brachioradialis tendon

\section{Anatomical variation of superficial radial nerve during free radial forearm flap harvest}

Sir,

Free Radial artery forearm flap (FRAFF) is one of the most common free flaps done by a plastic surgeon in the initial phase of reconstruction because of its relatively constant anatomy and superficial dissection. We recently encountered a variation during harvest of this flap, in which the superficial branch of radial nerve was replaced by the lateral cutaneous nerve of forearm. This is the first case in our series of more than 500 cases in the last 7 years.

During the radial forearm flap harvest we will encounter both the lateral cutaneous nerve of forearm (LCN) and the superficial branch of radial nerve (SRN). The LCN runs along with the cephalic vein in the proximal forearm and it provides most of the sensation to the flap region. ${ }^{[1]}$ This nerve is usually harvested with the flap and can be utilized to provide a sensate flap. The SRN supplies the

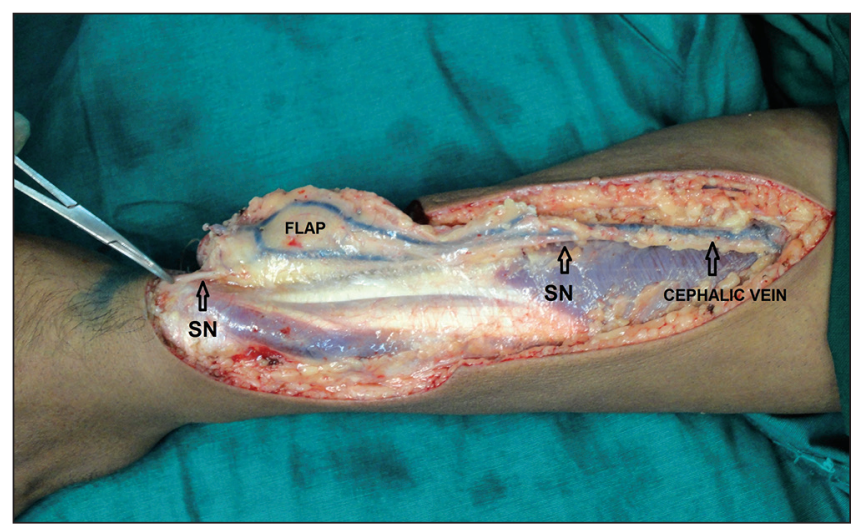

Figure 2: Intra-op: SN- Superficial nerve was found ulnar to Brachioradialis tendon

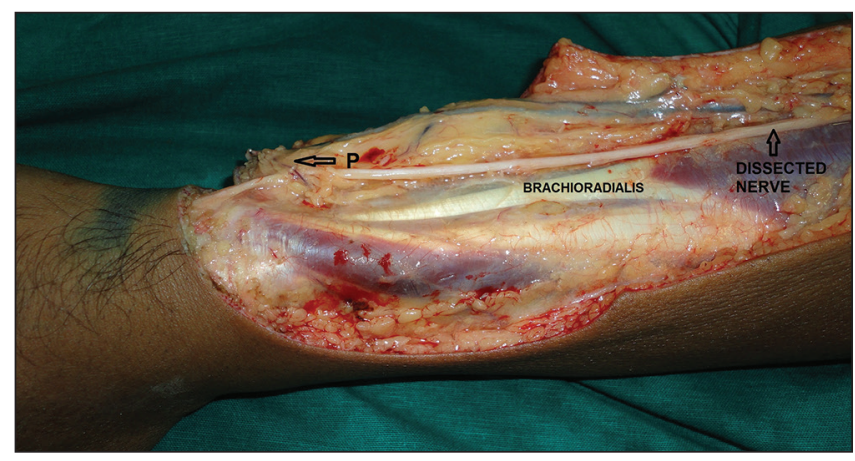

Figure 3: Intra-op: Entire nerve dissected. P- Perforator passing over nerve 


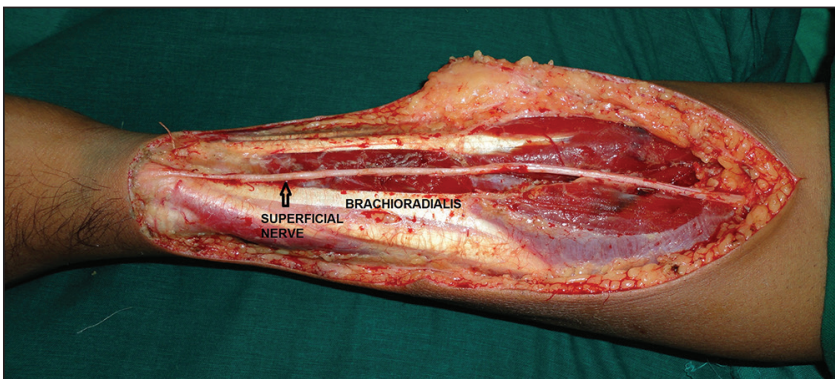

Figure 4: Entire course of nerve after flap harvest

There are many reports ${ }^{[2-6]}$ about the variation of the SRN. Knowledge of this anatomical variation will help in diagnostic neurophysiology, nerve transfers, guiding surgical incisions, trauma reconstructive surgery, Flap harvest and performing nerve blocks. ${ }^{[6]}$ Lindau et al. ${ }^{[7]}$ had a case in which the SRN was superficial to the brachioradialis muscle in its entire course. Yogesh et al., ${ }^{[8]}$ has mentioned a case of SRN replaced by the musculucutaneous nerve, but they have not mentioned the relation of the nerve to the brachioradialis muscle. Fortunately such variations are extremely rare, and the arterial anatomy being consistent. The message we want to convey is that in such situations, harvesting the nerve with the flap will lead to sensory loss in the dorsum of hand and take adequate precautions to protect the septocutaneous perforators while dissecting the nerve.

Vinay K. Shankhdhar, Prabha S. Yadav, Jaiswal Dushyant, Selva S. R. Sakthipalan

Department of Plastic and Reconstructive Services, Homi Bhabha Block, TATA Memorial Hospital, Parel, Mumbai, Maharashtra, India
Address for correspondence:

Dr. Selva S. R. Sakthipalan, Flat No. A-2, Amaravathi Appts., C-27, C Block $8^{\text {th }}$ Street, Annanagar East, Chennai - 600 102, Tamil Nadu, India. E-mail:dr_seetha39@yahoo.com

\section{REFERENCES}

1. Boutros S, Yuksel E, Weinfeld AB, Alford EL, Netscher DT. Neural anatomy of the radial forearm flap. Ann Plast Surg 2000;44:375-80.

2. Appleton AB. A case of abnormal distribution of the N. Musculocutaneus, with complete absence of the Ramus cutaneous $\mathrm{N}$. Radialis. J Anat Physiol 1911;46:89-94.

3. Huanmanop $\mathrm{T}$, Agthong $\mathrm{S}$, Luengchawapong $\mathrm{K}$, Sasiwongpakdee T, Burapasomboon P, Chentanez V. Anatomic characteristics and surgical implications of the superficial radial nerve. J Med Assoc Thai 2007;90:1423-9.

4. Samarakoon LB, Lakmal KC, Thillainathan S, Bataduwaarachchi VR, Anthony DJ, Jayasekara RW. Anatomical relations of the superficial sensory branches of the radial nerve: A cadaveric study with clinical implications. Patient Saf Surg 2011;5:28.

5. Tryfonidis M, Jass GK, Charalambous CP, Jacob S. Superficial branch of the radial nerve piercing the brachioradialis tendon to become subcutaneous: An anatomical variation with clinical relevance. Hand Surg 2004;9:191-5.

6. Abrams RA, Brown RA, Botte MJ. The superficial branch of the radial nerve: An anatomic study with surgical implications. J Hand Surg Am 1992;17:1037-41.

7. Lindau RH, Wax MK. Abnormal anatomy of the superficial branch of the radial nerve. Head Neck 2013;35:E262-3.

8. Yogesh A, Marathe R, Pandit S. Musculocutaneous nerve substituting for the distal part of radial nerve: A case report and its embryological basis. J Neurosci Rural Pract 2011;2:74-6.

\begin{tabular}{|l|l|}
\hline \multicolumn{2}{|c|}{ Access this article online } \\
\hline Quick Response Code: & Website: \\
\hline & www.ijps.org \\
\cline { 2 - 2 } & DOI: \\
\hline
\end{tabular}

